\title{
Effects of source-sink alteration by pruning on physiological parameters and fruit production of Rosa roxburghii Tratt. on the Yunnan-Guizhou Plateau in China
}

\author{
C. ZHANG ${ }^{+}$, K. YAN, L.Z. LIN, Y.M. FANG, and X.Y. ZHANG \\ Liupanshui Normal University, 553000 Liupanshui, Guizhou, China
}

\begin{abstract}
The formation of economic yield and fruit quality of Roxburgh rose (Rosa roxburghii Tratt.) depends essentially on its source-sink interaction. Thus, a pruning experiment was conducted to assess the effects of source-sink regulation on photosynthetic physiology and fruit yield of Roxburgh rose, which was of great significance to production. Cutting off vegetative branches reduced physiological fruit loss and malformed fruits but increased single fruit quality and yield. Results revealed that the stomatal characteristics, the composition of mesophyll tissue, and photosynthesis of leaves on reproductive branches were significantly affected by the ratio of the vegetative and reproductive shoots. Our data indicated that the source-sink ratio could reflect the balance between vegetative growth and reproductive growth of the tree during the whole fruit period. Fruit tree pruning had guiding significance for improving the fruit yield of Roxburgh rose.
\end{abstract}

Keywords: biomass; fruit development; photosynthesis; pruning; source-sink relationship.

\section{Introduction}

Generally, it is necessary to carry out post-harvest canopy removal to improve the light transmission and ventilation conditions of fruit trees in agricultural production to improve the disease and insect resistance and yield of fruit trees. Then the amount of pruning has become the key problem in production. Excessive pruning may lead to tree yellowing and affect the yield (Yang et al. 2002, Gao
2018), while small pruning may lead to the tree canopy and also affect the yield and quality (Kang et al. 2006). Hence, the pruning amount of fruit trees is a recultivation link that affects the yield, quality, and effective fruit-bearing life of trees. The change of the source-sink relationship had a more significant impact on fruit size than on fruit quality and other characteristics (Léchaudel et al. 2005, Wibbe and Blanke 1995, Poni et al. 2018). Long-shoot pruning increased water-use efficiency by decreasing stomatal

\section{Highlights}

- The source alternation can change the distribution of palisade cells and spongy mesophyll in functional leaves

- Different pruning methods had a significant effect on the photosynthesis of functional leaves

- $50 \%$ pruning was more valuable in Roxburgh rose
Received 9 October 2021

Accepted 11 January 2022

Published online 1 February 2022

${ }^{+}$Corresponding author

e-mail: zhangchaoscu@126.com

Abbreviations: $\mathrm{Chl}$ - chlorophyll; DAF - days after flowering; $C_{\mathrm{i}}$ - intercellular $\mathrm{CO}_{2}$ concentration; $E$ - transpiration rate; $\mathrm{F}_{0}-$ minimal fluorescence; $\mathrm{F}_{0}{ }^{\prime}$ - minimal fluorescence level in the light-adapted state; $\mathrm{F}_{\mathrm{m}}$ - maximal fluorescence; $\mathrm{F}_{\mathrm{m}}{ }^{\prime}$ - maximal fluorescence level in the light-adapted state; $F_{s}$ - steady-state fluorescence yield; $F_{v} / F_{m}-$ maximum photochemical efficiency of PSII; $g_{s}-$ stomatal conductance; MDA - malondialdehyde; NPQ - nonphotochemical quenching coefficient; $P_{\mathrm{N}}$ - net photosynthetic rate; POD peroxidase; $\mathrm{q}_{\mathrm{p}}$ - photochemical quenching; SOD - superoxide dismutase; $\Phi_{\mathrm{PSII}}$ - actual photochemical efficiency.

Acknowledgments: The research is supported by the Science and Technology Planning Project of Guizhou Provincial Science and Technology Department, China (Grant No. [2020] 1Y097); High-level Talent Introduction Project of Liupanshui Normal University (LPSSYKYJJ201806); and the Science and Technology Project of Liupanshui, China (Grant No. 52020-2021-PT-01).

Conflict of interest: The authors declare that they have no conflict of interest. 
conductance significantly and increasing carboxylation efficiency in Prunus persica var. Nectarina (Yang et al. 2002, Gao 2018). Crop load regulation affects the distribution of long and short branches of Prunus persica. Fruit thinning promotes growth distribution, which is similar to fruit removal. Fruit thinning is effective in increasing fruit size and aggravates the problem of tremor budding (Gordon and Dejong 2007). Cutting off the long shoots of Morus alba L. promotes the growth of short branches. Accordingly, the advantage of long shoots is maintained by the relevant control system acting on the top of long branches and short shoots (Suzuki and Kohno 1987).

After pruning Vaccinium spp. in summer, regardless of pruning time or intensity, it increased the nutritional growth vitality of blueberries and reduced the incidence of leaf diseases (Kovaleski et al. 2015). The source-sink relationship played an important role in fruit yield and fruit size distribution, which was one of the hot issues in the physiological research of the high-product fruit trees (Jorquera-Fontena et al. 2016). Pruning, thinning flowers and fruits, protecting flowers and fruits, fruit bagging techniques used in fruit tree cultivation and management were essentially based on the principle of the source-sink relationship (Poni et al. 2018). The economic yield of fruit trees mainly depended on the light energy capture efficiency of leaves and the operation and distribution of photosynthetic products (Iglesias et al. 2010). The relationship between sink and source was an important factor affecting the light energy capture and distribution mode of photosynthetic products (Cheng et al. 2009, Cui et al. 2010, Wertin et al. 2010).

Roxburgh rose (Rosa roxburghii Tratt.) is a unique wild plant in the mountains of Yunnan-Guizhou Plateau. Although it is born in a barren land, it contains a high nutritional value and is rich in various vitamins, trace elements, and amino acids (Yoshida et al. 1987, Fan et al. 2003, Wang et al. 2021). Roxburgh rose with yellow shell and covered with thorns is known as "wealth with thorns'. The development of the Roxburgh rose industry brings not only ecological benefits in typical karst landform areas but also economic and poverty alleviation benefits to China's ethnic minorities (Yoshida et al. 1987, Fan et al. 2003, Wang et al. 2021). The branches of the Roxburgh rose grow vigorously and the branch pruning method becomes a key problem in production. Excessive pruning of branches could lead to yellowing of trees and less flower bud formation, which would affect the yield (Pinkard and Beadle 1998, Zhang et al. 2014). Too little pruning of branches could cause tree shade and affect yield and quality (Pinkard and Beadle 1998, Zhang et al. 2014). Therefore, the pruning amount of Roxburgh rose is an important cultivation link affecting yield and quality.
Therefore, it is of great significance to further study the source-sink relationship and improve the economic value of Roxburgh rose by understanding the impact and role of the change of source-sink relationship on economic yield (Wang et al. 2021). This experiment can make a new attempt to improve the relationship between source and sink of Roxburgh rose to explore the effects of source regulation on photosynthetic characteristics and fruit yield on the Yunnan-Guizhou Plateau.

\section{Materials and methods}

Plant materials: The experiment was carried out from 2018 to 2020 in the research base of Liupanshui Normal College, Guizhou, China. In March 2018, the collected Roxburgh roses were transplanted from the edge of the farmland deep in the mountains $\left(26.69^{\circ} \mathrm{N}, 104.63^{\circ} \mathrm{E}\right)$ to the research base $\left(26.33^{\circ} \mathrm{N}, 104.57^{\circ} \mathrm{E}\right)$, which is located on the Yunnan-Guizhou Plateau, with an altitude of more than $1,800 \mathrm{~m}$; the site has a north subtropical monsoon humid climate.

The 3-year-old seedlings (142 strains) were transplanted to the field in 2018. The cultivation method of field fruit trees was arranged in a random block with a row spacing of $1.5 \times 2 \mathrm{~m}$. The orchard soil was mountain shrub meadow soil. The soil composition is shown in the text table. A compound fertilizer at $8.5 \mathrm{~g} \mathrm{~m}^{-2}$ was applied before flowering while a complex fertilizer $\left(\mathrm{N}_{-} \mathrm{P}_{2} \mathrm{O}_{5}-\right.$ $\mathrm{K}_{2} \mathrm{O}$ ) at $0.225 \mathrm{~kg} \mathrm{~m}^{-2}$ was applied after harvest in autumn. During the whole growth process, the soil water content was kept at $17.5 \%$ and the ground was covered with plastic film to inhibit the growth of weeds. In 2018, the fruit trees grew normally, and some of them blossomed and borne fruit to complete the life cycle. It continued to grow until 2019, when all fruit trees bloomed and borne fruit and the yield was $1.5 \mathrm{~kg} \mathrm{~m}^{-2}$. Therefore, it was inferred that fruit trees had entered the peak period of reproduction. The pruning experiment was carried out in 2020 and the shoots bloomed on 4-9 May 2020. The meteorological data in 2020 are shown in Fig. 1. On 7 June 2020 (35 d after flowering, $35 \mathrm{DAF}$; Fig. $1 E$ ), the early stage of fruit development, the treatments started. At that point, all flowers faded, and Roxburgh rose grew small fruits. In total four treatments were established (Yang et al. 2002): (1) $0 \%$ of the vegetative branches were cut off manually (CK); (2) cut 25\% (T1); (3) cut 50\% (T2); and (4) cut 75\% (T3). Each treatment included 12 plants and a completely randomized block design was used. The height of the 5-year-old fruit tree was between 1.4-1.6 m. It was a cluster of small shrubs without obvious trunk branches. There were reproductive branches and vegetative branches on each cluster branch. In the pruning experiment, the

\begin{tabular}{lllllll}
\hline Sampling depth & $\begin{array}{l}\text { Soil water content } \\
{[\%]}\end{array}$ & $\begin{array}{l}\text { Nitrogen } \\
{\left[\mathrm{g} \mathrm{kg}^{-1}\right]}\end{array}$ & $\begin{array}{l}\text { Phosphorus } \\
{\left[\mathrm{g} \mathrm{kg}^{-1}\right]}\end{array}$ & $\begin{array}{l}\text { Potassium } \\
{\left[\mathrm{g} \mathrm{kg}^{-1}\right]}\end{array}$ & $\mathrm{pH}$ & $\begin{array}{l}\text { Organic matter } \\
{\left[\mathrm{g} \mathrm{kg}^{-1}\right]}\end{array}$ \\
\hline $0-20 \mathrm{~cm}$ & $17.91 \pm 1.13$ & $0.44 \pm 0.04$ & $0.16 \pm 0.01$ & $3.35 \pm 1.03$ & $5.92 \pm 0.35$ & $6.75 \pm 0.41$ \\
$20-40 \mathrm{~cm}$ & $17.48 \pm 1.02$ & $0.21 \pm 0.02$ & $0.10 \pm 0.01$ & $2.45 \pm 1.03$ & $5.31 \pm 0.39$ & $4.33 \pm 0.29$ \\
\hline
\end{tabular}



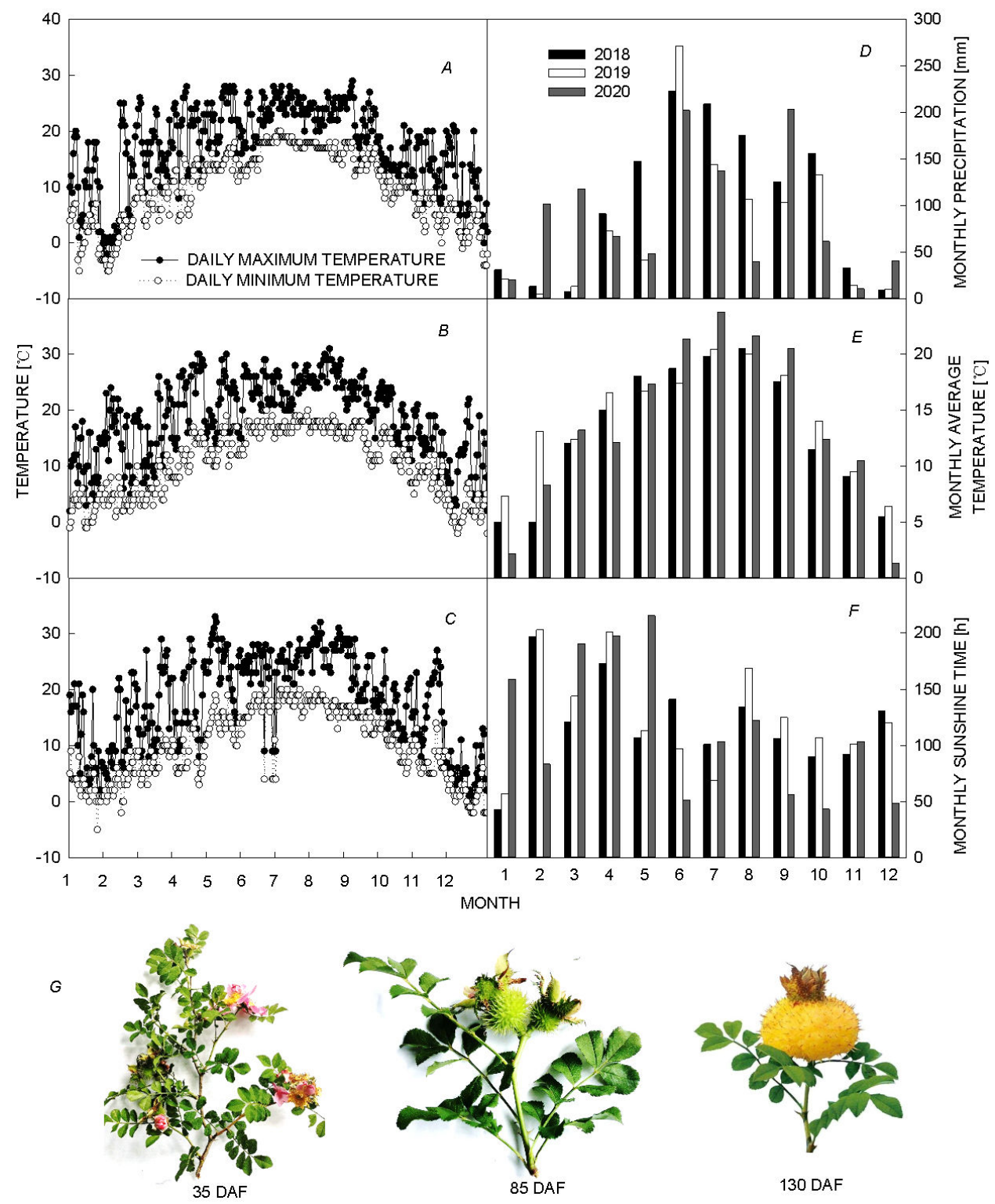

130 DAF

Fig. 1. Meteorological data of the scientific research base. The changing trend of daily maximum temperature and minimum temperature in $2018(A), 2019(B)$, and $2020(C) ;(D)$ monthly precipitation; $(E)$ monthly average temperature; $(F)$ monthly sunshine hours; and $(G)$ reproductive branch growth of fruit trees after 35, 85, and $130 \mathrm{~d}$ after flowering in 2020.

vegetative branches on each cluster branch were evenly cut from bottom to top. Field management, irrigation, and fertilization were consistent with 2018 and 2019.

Leaf anatomical structures and stomatal characteristics: On 27 July 2020 (85 DAF), we measured leaf stomata and the structure of Roxburgh rose in the middle stage of fruit development (Fig. 1). The embryo was fully developed, and the fruit development was slow, which generally lasted about $40 \mathrm{~d}$.

The paraffin section was prepared according to Lee et al. (2007). We cut small leaf segments $(2 \times 2 \mathrm{~mm})$ from the odd-pinnately compound leaf (top leaves) of the reproductive branches in Roxburgh rose and immersed these small leaf segments in a fixative solution consisting of $5 \%(\mathrm{v} / \mathrm{v})$ formaldehyde, $5 \%(\mathrm{v} / \mathrm{v})$ glacial acetic acid, and $70 \%(\mathrm{v} / \mathrm{v})$ ethanol, soaked at $4{ }^{\circ} \mathrm{C}$ until the leaves turned white. After that, the leaves were dehydrated using graded ethanol series ( $J J-12 J$, China), embedded in paraffin (JB-P5, China), and stained with Safranin O-Fast Green. Lateral sections were prepared using a rotary microtome (Leica-RM2016, Germany), observed under an optical microscope (Olympus-BX51, Japan), and photographed using a high-list counter camera (Nikon-D7000, Japan). The thickness and area of epidermal cells, palisade cells, spongy mesophyll, and vascular bundles were measured according to Zhang et al. (2019), using the Image J software. The stomatal characteristics were measured 
according to $\mathrm{Wu}$ et al. (2014). Nail polish was applied to the abaxial side of Roxburgh rose leaves to obtain replicas of the stomata (the adaxial side of the leaf has no pores). Then the replicas were observed (Olympus-BX51, Japan) and photographed (Nikon-D7000, Japan). The stomatal density and size were measured according to Zhang et al. (2019), using Spot32 software.

Agronomic and physiological parameters: On 7 June 2020 (35 DAF) (Fig. 1E), the physiological fruit-drop rate was counted at the final flowering stage (the early fruit development). On 27 July 2020 (85 DAF), the fruit-setting rate was calculated in the middle stage of fruit development. The number of fruits per plant was investigated before harvest. On 10 September 2020 (130 DAF), we measured the yield per plant, counted the number of shaped fruits per plant, and measured the single fruit mass and the output of the whole plant at the time of fruit harvest (the later stage of fruit development). On 27 July 2020 (85 DAF), the leaf area of each leaflet of the odd-pinnately compound leaf was measured by Image $J$ software, and the mass of each leaflet was determined by high precision analytical balance.

The photosynthetic pigment of leaves was extracted with a mixture of $80 \%$ acetone and $95 \%$ alcohol in the ratio of $1: 1$, then was determined by spectrophotometry (Shimadzu-UV 2600, Japan) (Zhang and Kirkham 1994). Similarly, malondialdehyde (MDA) was also determined by spectrophotometry (Zhang and Kirkham 1994). The soluble sugar content, SOD (superoxide dismutase, EC 1.15.1.1) activity, and POD (peroxidase, EC 1.11.1.7) activity were determined according to Zhang and Kirkham (1994).

Leaf gas exchange and chlorophyll (Chl) fluorescence parameters: We measured gas exchange and Chl fluorescence parameters of Roxburgh rose in 85 DAF. Photosynthetic parameters were measured using a portable infrared gas analyzer ( $\mathrm{Li}$-Cor 6400, USA) from 23-30 July 2020 (sunny day). We measured the parameters from 10:00 to $12: 00 \mathrm{~h}$ in Beijing. $P_{\mathrm{N}}$ (net photosynthetic rate), $g_{\mathrm{s}}$ (stomatal conductance), $C_{\mathrm{i}}$ (intercellular $\mathrm{CO}_{2}$ concentration), and $E$ (transpiration rate) were measured at a set temperature of $20^{\circ} \mathrm{C}$ (as shown in Fig. 1: the temperature at high-altitude areas is cold, and the average temperature in May 2020 is $19.6^{\circ} \mathrm{C}$ ), a set $\mathrm{CO}_{2}$ concentration $\left(360 \mu \mathrm{mol} \mathrm{mol}{ }^{-1}\right)$, and a set light conditions $\left[\mathrm{PAR}=1,800 \mu \mathrm{mol}\right.$ (photon) $\mathrm{m}^{-2} \mathrm{~s}^{-1}$, near the light-saturation point of Roxburg rose. $\mathrm{F}_{0}$ (the minimal fluorescence) and $\mathrm{F}_{\mathrm{m}}$ (the maximal fluorescence) were measured from 5:00-6:00 h with a Chl fluorescence leaf chamber $(\mathrm{Li}-\mathrm{Cor}$ 6400-40, USA). Then, $\mathrm{F}_{0}$ ' (the minimal fluorescence level in the light-adapted state), $\mathrm{F}_{\mathrm{m}}$ ' (the maximal fluorescence level in the light-adapted state), and $\mathrm{F}_{\mathrm{s}}$ (steady-state fluorescence yield) ( $\mathrm{Li}$-Cor 6400-40, USA) were obtained from the leaves between 10:00 to $12: 00 \mathrm{~h}[\mathrm{PAR}=1,800$ $\mu \mathrm{mol}\left(\right.$ photon) $\mathrm{m}^{-2} \mathrm{~s}^{-1}$.

Statistical analysis: There were more than eight repetitions for each data in the experiment. The original data was collated by using WPS Office 2019 Mac (Kingsoft Document, China). Then, comparisons, analysis, and differences between the groups were performed with SPSS 19.0 (IBM, USA). The difference was considered significant at $P<0.05$. The graphs were drawn using SigmaPlot 14.0 (Systat Software Inc., USA).

\section{Results}

\section{Effect of cutting vegetative branches on stomatal characteristics of reproductive branches}

After a period of light, photosynthetic organs were activated and stomata opened to promote gas exchange, conducive to the gas exchange of photosynthesis. By observing the replicas of the stomata on the adaxial and abaxial surfaces of hundreds of Roxburgh rose leaves, we found that there was no stomatal distribution on the adaxial surface of the leaves on the reproductive branches, and all stomata were distributed only on the abaxial surface (Fig. 2A,B). The results showed that the leaf stomatal density of CK (cutting $0 \%$ ) trees was high, but the stomata area was small, with an average of $107.78 \mu \mathrm{m}^{2}$ (Fig. $2 C, G$ ). Compared to $\mathrm{CK}$, the stomatal density decreased by $18.8 \%$ and the stomatal area increased by $78.1 \%$ in $\mathrm{T} 1$ (cutting $25 \%$ ). The stomatal density decreased by $31.3 \%$ and the stomatal area increased by $208.5 \%$ in T2 (cutting 50\%), while the stomatal density decreased by $32.1 \%$ and the stomatal area increased by $74.6 \%$ in $\mathrm{T} 3$ (cutting $75 \%$ ) (Fig. 2D,G).

\section{Effects of different pruning methods on leaf palisade cells}

The mesophyll cells of leaves on the reproductive branches were closely arranged and the palisade tissue was located under the upper epidermis, which was composed of parenchyma cells containing a large number of chloroplasts (Fig. $3 A$ ). The whole leaf structure without pruned vegetative branches consisted of five parts: the epidermis on the adaxial side, the epidermis on the abaxial side, vascular bundle, palisade cells, and sponge mesophyll, accounting for $10.2,8.8,6.2,48.0$, and $26.9 \%$, respectively (Fig. $3 B$ ). The palisade cell was up to $1 / 2$ of the leaf thickness. The cells of the palisade parenchyma became longer and spongy mesophyll cells became larger after pruning vegetative branches (Fig. 3C). Compared with CK, the palisade cells of T1, T2, and T3 increased by $8.9,11.7$, and $4.7 \%$, respectively (Fig. 3C). Compared with $\mathrm{CK}$, the ratio of palisade cells to spongy mesophyll in T1, $\mathrm{T} 2$, and $\mathrm{T} 3$ increased by $8.6,12.3$, and $28.8 \%$, respectively (Fig. 3E).

\section{Difference of leaf growth under different pruning methods}

Long-shoot pruning increased leaf thickening and leaf mass (Fig. 4A). Compared with CK, the leaf thickness of $\mathrm{T} 1, \mathrm{~T} 2$, and $\mathrm{T} 3$ increased by $36.7,45.1$, and $58.1 \%$, 


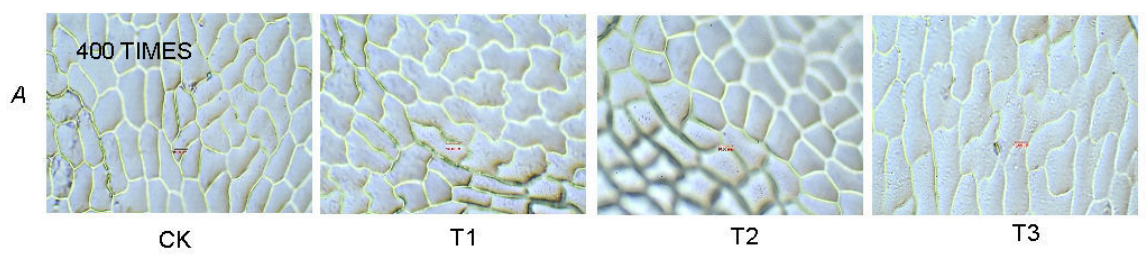

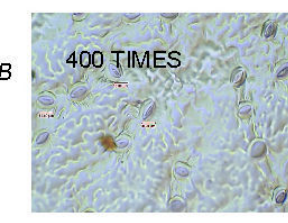

CK

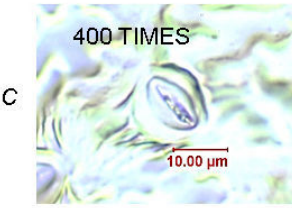

$\mathrm{CK}$

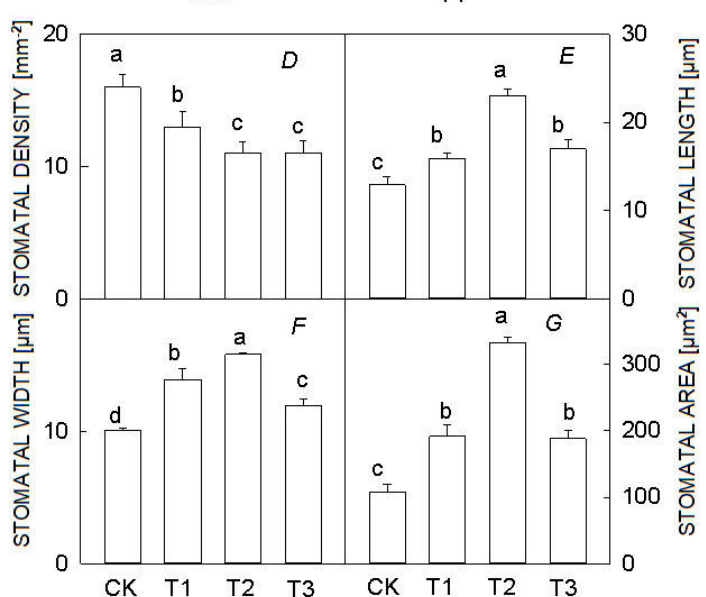

respectively (Fig. $4 A$ ). Compared with CK, the leaf mass in $\mathrm{T} 1, \mathrm{~T} 2$, and $\mathrm{T} 3$ increased by $10.5,29.9$, and $42.7 \%$, respectively (Fig. 4B). There was no significant difference in the leaf area (Fig. 4C) and RWC (Fig. 4D). Compared with $\mathrm{CK}$, the leaf chlorophyll content of $\mathrm{T} 1, \mathrm{~T} 2$, and $\mathrm{T} 3$ increased by $25.9,34.8$, and $12.3 \%$, respectively (Fig. $4 E$ ). Compared with $\mathrm{CK}$, the ratio of $\mathrm{Chl}$ to carotenoid content in $\mathrm{T} 1, \mathrm{~T} 2$, and $\mathrm{T} 3$ decreased by $11.0,15.1$, and $2.1 \%$, respectively (Fig. 4H). The MDA content increased after cutting vegetative branches (Fig. 4I). The change of source-sink ratio affected differently the MDA content in Roxburgh rose. Changing the source-sink ratio changed the soluble sugar content of leaves. Cutting off vegetative branches promoted the accumulation of soluble sugar (Fig. 4G). Changing the source-sink ratio had a significant effect on the SOD activity of Roxburgh rose, and the SOD activity decreased almost linearly (Fig. $4 K$ ). The activity of the POD was enhanced in the leaves of vegetative branches (Fig. $4 L$ ). After cutting $50 \%$, the activity of SOD in Roxburgh rose leaves was lower than that of CK, but the activity of POD was higher than that of CK (Fig. 4C).
Fig. 2. Stomatal characteristics. Image of leaf stomata on the adaxial side $(A)$ and abaxial side $(B)$ at a magnification of 400 times; $(C)$ stomatal size on the abaxial side; $(D)$ stomatal density, $(E)$ stomatal length, $(F)$ stomatal width, and $(G)$ stomatal area (mean $\pm \mathrm{SE}, n=8, P<0.05$ ). Scale bar $=10 \mu \mathrm{m}$.

\section{Effects of different pruning methods on the photosynthetic capacity of leaves}

The photosynthesis of Roxburgh rose was significantly affected by the ratio of the vegetative and reproductive shoot. $P_{\mathrm{N}}$ (Fig. $5 A$ ), $g_{\mathrm{s}}$ (Fig. $\left.5 B\right), E$ (Fig. $5 D$ ), and $\Phi_{\text {PSII }}$ (Fig. $5 F$ ) increased by long-shoot pruning. The fruit trees under cutting $50 \%$ vegetative branches had a reasonable light configuration, and $P_{\mathrm{N}}, g_{\mathrm{s}}, E$, and $\Phi_{\mathrm{PSII}}$ were higher than in the other treatments. Specifically, compared with CK, $P_{\mathrm{N}}$ increased by $34.1 \%, g_{\mathrm{s}}$ increased by $62.7 \%, E$ increased by $60.1 \%$, and $\Phi_{\text {PSII }}$ increased by $40.0 \%$ after cutting $50 \%$. Cutting off vegetative branches can effectively improve the photosynthesis of reproductive branches of Roxburgh rose (see Fig. 5). Changing the source-sink ratio affected the photosynthetic capacity of leaves on the reproductive branches. The photosynthetic capacity of leaves was the result of a comprehensive response to various factors. $P_{\mathrm{N}}$ and $g_{\mathrm{s}}$ increased, but $C_{\mathrm{i}}$ decreased after cutting $50 \%$. On the contrary, $P_{\mathrm{N}}$ and $g_{\mathrm{s}}$ decreased, but $C_{\mathrm{i}}$ increased after cutting $75 \%$ (Fig. 5). 


\section{A}

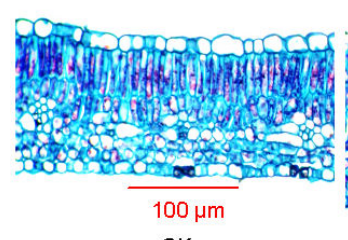

CK

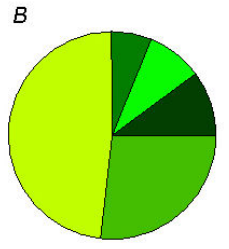

CK

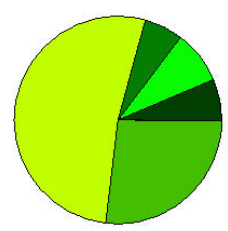

T1
T1

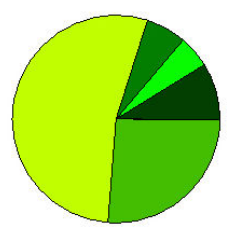

T2

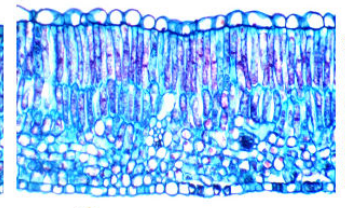

$\mathrm{T} 2$

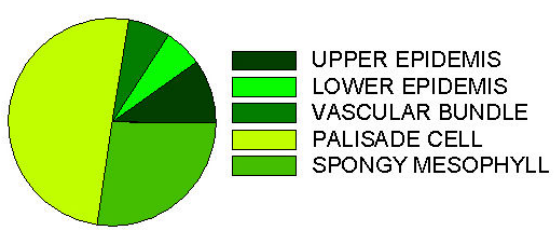

T3

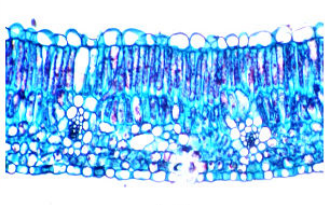

T3
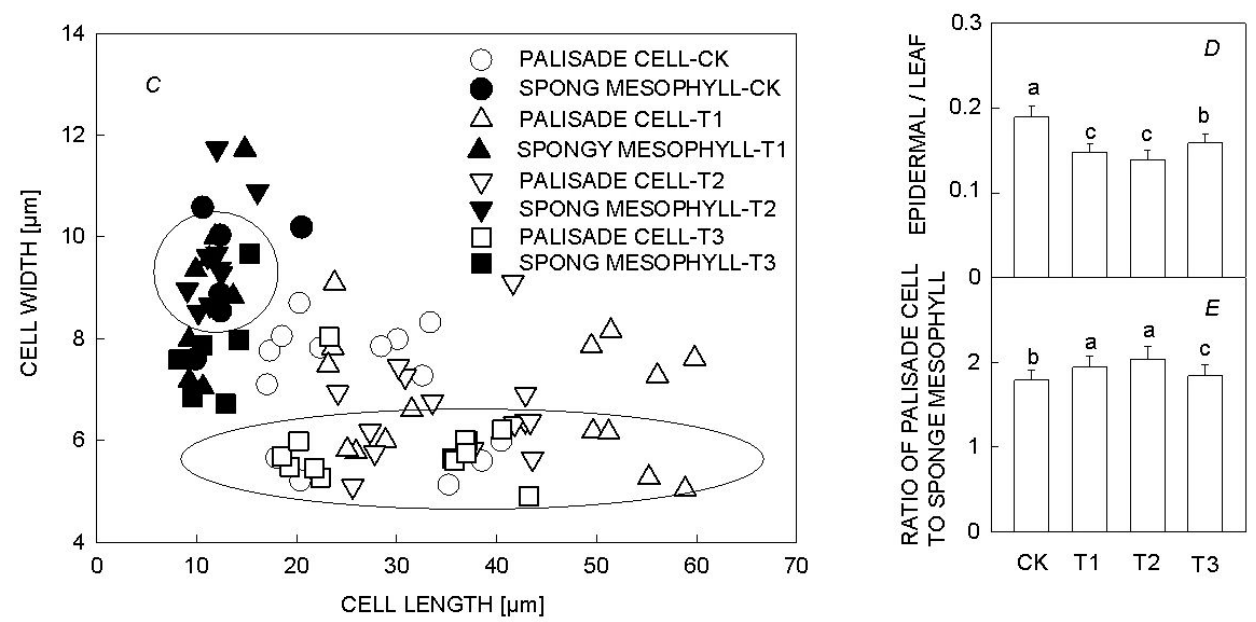

Fig. 3. The changes of leaf microstructure after different pruning treatments. $(A)$ Leaf anatomy at a magnification of 200 times. Views of the palisade tissue and spongy mesophyll of leaves are shown. Scale bar $=100 \mu \mathrm{m}$. $(B)$ Leaf composition, the color of each part of pie charts represents the percentage of epidermis on adaxial side, epidermis on abaxial side, vascular bundle, palisade cells, and sponge mesophyll, respectively. The sum of these five parts is $100 \%$, representing the whole leaf structure. $(C)$ Length and width of mesophyll cells in a field of the same size; $(D)$ the ratio of epidermis cell to leaf; and $(E)$ the ratio of palisade cell to spongy mesophyll (mean \pm $\mathrm{SE}, n=8, P<0.05)$.
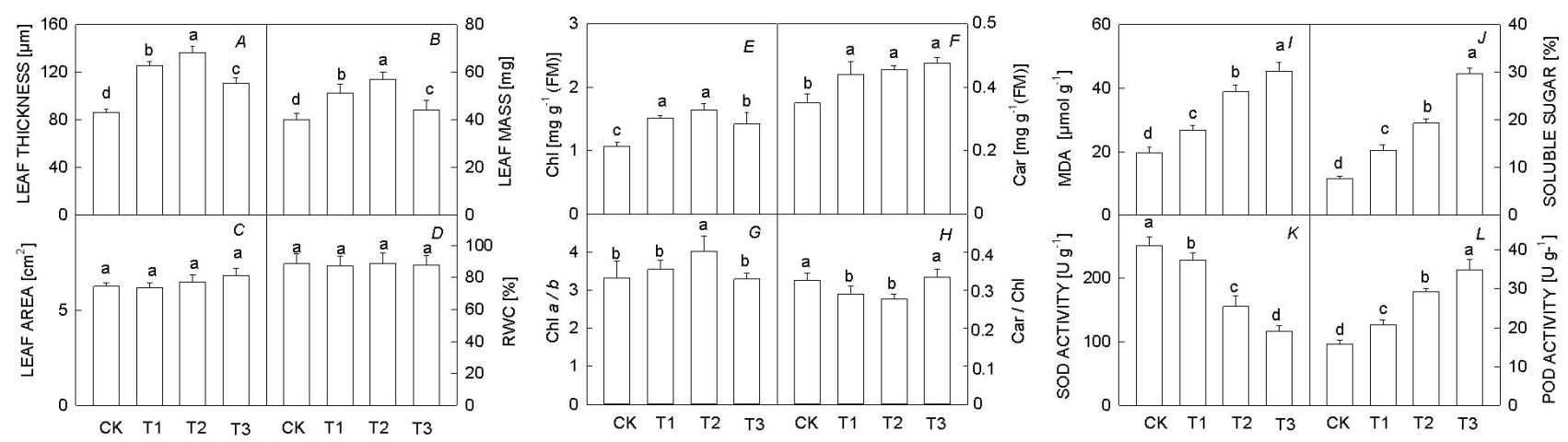

Fig. 4. Leaf physiological changes after pruning. Leaf growth, including $(A)$ leaf thickness, $(B)$ leaf mass, $(C)$ leaf area, and $(D)$ relative water content (RWC). Photosynthetic pigment parameters, including $(E)$ chlorophyll content, $(F)$ carotenoid content, $(G)$ ratio of chlorophyll $a / b$, and $(H)$ ratio of chlorophyll to carotenoid. $(I)$ malondialdehyde (MDA) content, $(J)$ soluble sugar content, $(K)$ superoxide dismutase (SOD) activity, and $(L)$ peroxidase (POD) activity (mean $\pm \mathrm{SE}, n=8, P<0.05$ ). 


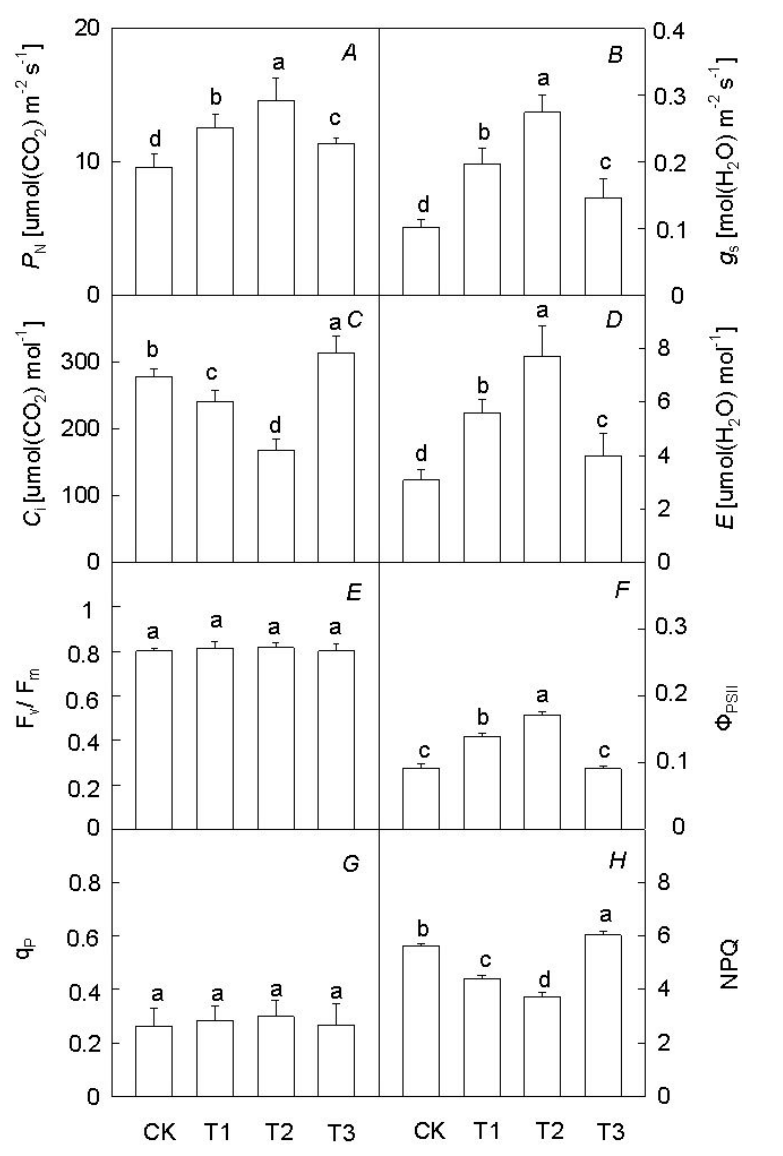

Fig. 5. The differences in gas-exchange parameters of leaves after using different pruning methods, including $(A)$ net photosynthetic rate $\left(P_{\mathrm{N}}\right),(B)$ stomatal conductance $\left(g_{\mathrm{s}}\right),(C)$ intercellular $\mathrm{CO}_{2}$ concentration $\left(C_{\mathrm{i}}\right)$, and $(D)$ transpiration rate $(E)$. The chlorophyll fluorescence parameters of leaves in different pruning methods, including $(E)$ maximum photochemical efficiency of PSII $\left(\mathrm{F}_{\mathrm{v}} / \mathrm{F}_{\mathrm{m}}\right)$, $(F)$ actual photochemical efficiency $\left(\Phi_{\mathrm{PSII}}\right),(G)$ photochemical quenching $\left(\mathrm{q}_{\mathrm{p}}\right)$, and $(H)$ nonphotochemical quenching (NPQ) $\left[\mathrm{PAR}=1,800 \mu \mathrm{mol}\right.$ (photon) $\mathrm{m}^{-2} \mathrm{~s}^{-1}$, mean $\left.\pm \mathrm{SE}, n=8, P<0.05\right]$.

\section{Differences in yield components of Roxburgh rose under different pruning methods}

The fruit gradually developed and the fruit volume became larger after flowering (Fig. 6A). The peel color changed from green to gold. The unique spines of Roxburgh rose fruit became longer and harder, emitting a charming aromatic smell. Cutting off vegetative branches significantly reduced the physiological fruit drop (Fig. 6C), reduced malformed fruits (Fig. 6E), improved the fruit-setting rate (Fig. 6B), increased the number of seeds (Fig. 6D), single fruit quality (Fig. 6F), and yield (Fig. 6G). When 50\% of vegetative branches were cut off, the yield was the highest. Compared with $\mathrm{CK}$, the physiological fruit-drop rate was reduced by $2.71 \%$, the fruit-setting rate increased by $17.77 \%$, the percentage of malformed fruit decreased by $31.45 \%$, the average fruit quality increased by $23.48 \%$, and the yield per plant increased by $15.21 \%$ after cutting $50 \%$.
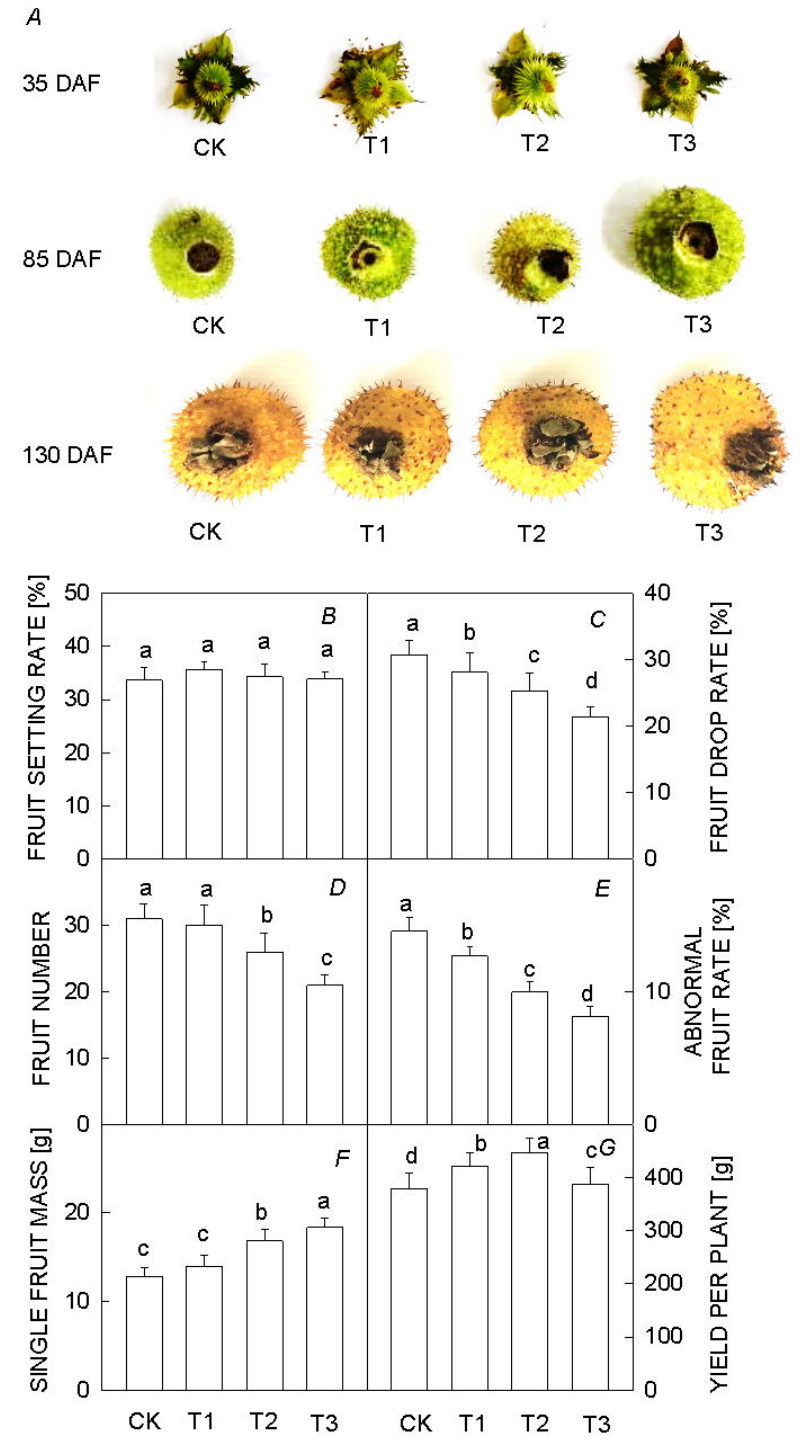

Fig. 6. Yield composition of Roxburgh rose. (A) Comparison of fruits after 35,55 , and $85 \mathrm{~d}$ of flowering; the yield composition parameters, including $(B)$ fruit-setting rate, $(C)$ fruit-drop rate, $(D)$ fruit number, $(E)$ malformed-fruit rate, $(F)$ single fruit quality, and $(G)$ yield per plant, respectively (mean $\pm \mathrm{SE}, n=8, P<0.05$ ).

\section{Discussion}

Pruning optimized the canopy structure and increased the yield of Roxburgh rose

In actual production, pruning the branches of fruit trees could significantly improve the canopy structure, increase the light transmission performance, and then improve the yield (Inoue et al. 2008). Roxburgh rose obtained ideal light conditions, and its fruit mass was the highest; thus, we achieved the expected effect of improving the quality under 50\% pruning. After over-pruning at $75 \%$, fruit trees showed some problems, such as yellowing of leaves during fruit set. This shows that excessive pruning has a certain 
negative effect and harms the plant. Spraying certain foliar fertilizer during fruit set might have a certain effect on its yellowing (Guillermo et al. 2007, Parvizi and Sepaskhah 2015). In the $50 \%$ pruning mode, the single fruit mass and yield of Roxburgh rose were the largest. Considering the quality, yield, and plant growth, 50\% pruning was more valuable. The economic yield of Roxburgh rose was determined by the fruit size (Zhang et al. 2014). The physiological fruit loss of Roxburgh rose was significantly reduced, the number of malformed fruits was reduced, the fruit-setting rate was improved, and the single fruit quality and yield increased under the treatment of reducing vegetable branches. Fruit size primarily depends on fruit load (Huang et al. 2017). In addition, the fruit size was related to the age of the fruiting branch, fruit-setting node, fruit thinning degree, time, and harvest time (Iglesias et al. 2010, Dash et al. 2013). Appropriate fruit load has played an essential role in improving fruit quality (McClure and Cline 2015). The green part of the fruit before ripening could also undergo photosynthesis and be used for its development (Wertin et al. 2010). Photosynthetic products of peel in Citrus reticulata Blanco were used primarily for the development of fruit itself, reduced the dependence on leaf photosynthetic products, and partially increased the accumulation of fruits (Mataa and Tominaga 1998, Iglesias et al. 2010).

\section{The relationship between photosynthetic capacity and yield of Roxburgh rose}

Initially, the light transmittance of the lower part of fruit trees weakened under $25 \%$ pruning. Subsequently, the reproductive growth was weakened relative to the vegetative growth, the vegetative growth of fruit trees was prosperous, and ultimately, the fruits of Roxburgh rose were reduced. The lack of light at the lower part of the plant may be the direct reason for the lowest yield of Roxburgh rose. Due to this, it is necessary to control properly the vegetative growth of the lower part during the growing season, especially in the fruit-setting period. The key to obtaining high-quality fruits is to improve the light transmittance at the lower part by removing dense branches. Different pruning methods lead to different photosynthetic capacities of reproductive branches, which may be related to the storage capacity, the speed and capacity of photosynthetic product transfer, and the growth stage (Borrás et al. 2004, Cheng et al. 2009, Choi et al. 2012). There was a close relationship between source and sink in the synthesis, transport, and distribution of photosynthetic products in the vegetative and reproductive branches of Roxburgh rose (Wibbe and Blanke 1995, Borrás et al. 2004, Morais et al. 2004, Matsuda et al. 2011, von Bennewitz et al. 2011, McClure and Cline 2015). Cutting off some vegetative branches increased leaf vitality and activity, reduced the assimilate accumulation in Lycopersicon esculentum, and then affected leaf activity (Matsuda et al. 2011, Jan and Kawabata 2011, Bénard et al. 2015).

\section{Effect of pruning on antioxidant enzyme activity in Roxburgh rose}

MDA is the final product of membrane lipid peroxidation and one of the essential biochemical indexes reflecting the degree of biomembrane damage (Zhang et al. 2014). At this time, the content of free radicals in leaves was relatively high and the biomembrane was extensively damaged (Sairam et al. 1997, Liu et al. 2012, Małecka et al. 2019). SOD and POD are necessary protective enzymes (Sairam et al. 1997, Liu et al. 2012, Małecka et al. 2019). The change of source-sink relationship affected the protective enzyme activity (Fig. 7). It shows that either source reduction could affect the free radical scavenging of plants (Liu et al. 2012). SOD and POD, as the key antioxidative enzymes of the cell membrane, maintain the steady-state level of free radical content of Roxburgh rose through synergistic effect, which is within the range of source-sink ratio to a certain extent, but when the source-sink ratio is too small, the cell membrane will still be damaged. The content of MDA in the flag leaf of Triticum aestivum L. was lower than that in pruning treatment after the change of source-sink ratio (Sairam et al. 1997). The activities of SOD and POD in Vitis vinifera L. (Chen et al. 2020) and Gossypium hirsutum L. (Kornyeyev et al. 2010) were lower than those of CK in the same period after cutting leaves.

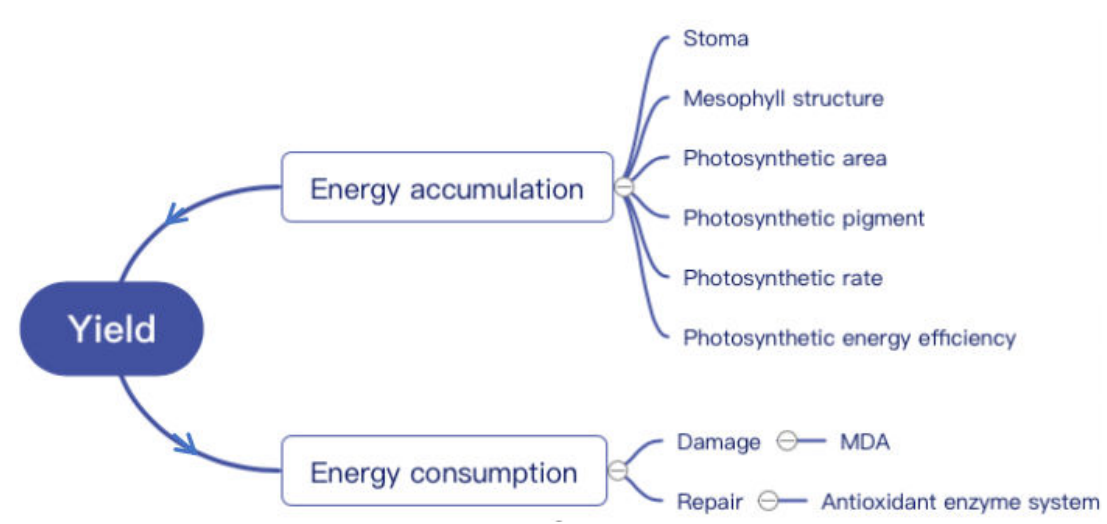

Fig. 7. Effects of source alteration on photosynthetic characteristics and fruit production. 
In summary, the photosynthetic capacity of Roxburgh rose was improved, the storage and transport capacity of carbohydrates in fruit trees was promoted, and the mass of single fruit and the yield of single fruit increased after cutting 50\%. The source-sink ratio could reflect the balance between vegetative growth and reproductive growth of the tree during the whole fruit period. Fruit tree pruning had guiding significance for improving the fruit yield of Roxburgh rose.

\section{References}

Bénard C., Bernillon S., Biais B. et al.: Metabolomic profiling in tomato reveals diel compositional changes in fruit affected by source-sink relationships. - J. Exp. Bot. 66: 3391-3404, 2015.

Borrás L., Slafer G.A., Otegui M.E.: Seed dry weight response to source-sink manipulations in wheat, maize and soybean: a quantitative reappraisal. - Field Crop. Res. 86: 131-146, 2004.

Chen Z., Gao Z., Sun Y. et al.: Analyzing the grape leaf proteome and photosynthetic process provides insights into the injury mechanisms of ozone stress. - Plant Growth Regul. 91: 143$155,2020$.

Cheng J., Fan P., Liang Z. et al.: Accumulation of end products in source leaves affects photosynthetic rate in peach via alteration of stomatal conductance and photosynthetic efficiency. J. Am. Soc. Hortic. Sci. 134: 667-676, 2009.

Choi E.-Y., Cho I.-H., Moon J.-H., Woo Y.-H.: Impact of secondary-lateral branch removal during watermelon production. - Hortic. Environ. Biote. 53: 24-31, 2012.

Cui P.Q., Jiang W.B., Weng M.L. et al.: [Pigment contents and net photosynthetic rates of leaves in purple-leaf plum seedling under shading.] - Acta Bot. Bor.-Occident. Sin. 30: 22862292, 2010. [In Chinese]

Dash M., Johnson L.K., Malladi A.: Reduction of fruit load affects early fruit growth in apple by enhancing carbohydrate availability, altering the expression of cell production-related genes, and increasing cell production. - J. Am. Soc. Hortic. Sci. 138: 253-262, 2013.

Fan W.G., An H.M., Liu G.Q. et al.: [Changes of endogenous hormone contents in fruit, seeds and their effects on the fruit development of Rosa roxburghii.] - Agr. Sci. China 12: 13761381, 2003. [In Chinese]

Gao Y.: [Effects of long branch pruning on peach growth and fruit quality.] - Agr. Tech. China 38: 2, 2018. [In Chinese]

Gordon D., Dejong T.M.: Current-year and subsequent-year effects of crop-load manipulation and epicormic-shoot removal on distribution of long, short and epicormic shoot growth in Prunus persica. - Ann. Bot.-London 99: 323-332, 2007.

Guillermo J.P.M., Reyes C.H., Aguilar H. et al.: Effect of the foliar application of fertilizers and phytoregulators on the setting and development of 'Kent' mango fruits. - Exp. Cell. Res. 80: 354-360, 2007.

Huang L., Zhang Q., Zhang Z. et al.: Overview of relation between mineral nutrient elements and growth and development of fruit trees. - Asian Agr. Res. 9: 75-81, 2017.

Iglesias D.J., Lliso I., Tadeo F.R., Talon M.: Regulation of photosynthesis through source: sink imbalance in citrus is mediated by carbohydrate content in leaves. - Physiol. Plantarum 116: 563-572, 2010.

Inoue K., Imura M., Ozaki Y.: Effects of pinching and lower branch pruning on yield of spears in semi-forcing green asparagus (Asparagus officinalis L.) cultivation. - Hortic. Res. 7: 87-90, 2008.
Jan N.E., Kawabata S.: Relationship between fruit soluble solid content and the sucrose concentration of the phloem sap at different leaf to fruit ratios in tomato. - J. Jpn. Soc. Hortic. Sci. 80: 314-321, 2011

Jorquera-Fontena E., Alberdi M., Reyes-Díaz M., Franck N.: Rearrangement of leaf traits with changing source-sink relationship in blueberry (Vaccinium corymbosum L.) leaves. Photosynthetica 54: 508-516, 2016.

Kang Y.Q., Liu G.J., Li S.H. et al.: [Observation on fruit branch growth in different directions and lengths of long branch pruned peach.] - China Fruits 4: 24-26, 2006. [In Chinese]

Kornyeyev D., Logan B.A., Payton P. et al.: Enhanced photochemical light utilization and decreased chilling-induced photoinhibition of photosystem II in cotton overexpressing genes encoding chloroplast-targeted antioxidant enzymes. Physiol. Plantarum 113: 323-331, 2010.

Kovaleski A.P., Darnell R.L., Casamali B., Williamson J.G.: Effects of timing and intensity of summer pruning on vegetative traits of two southern highbush blueberry cultivars. HortScience 50: 1486-1491, 2015.

Léchaudel M., Génard M., Lescourret F. et al.: Modeling effects of weather and source-sink relationships on mango fruit growth. - Tree Physiol. 25: 583-597, 2005.

Lee S.-H., Tewari R.K., Hahn E.-J., Paek K.-Y.: Photon flux density and light quality induce changes in growth, stomatal development, photosynthesis and transpiration of Withania somnifera (L.) Dunal. plantlets. - Plant Cell Tiss. Org. Cult. 90: 141-151, 2007.

Liu S., Ma M., Pan Y. et al.: Effects of light regimes on photosynthetic characteristics and antioxidant system in seedlings of two alder species. - Chin. J. Plant Ecol. 36: 10621074, 2012. [In Chinese]

Małecka A., Konkolewska A., Hanć A. et al.: Insight into the phytoremediation capability of Brassica juncea (v. Malopolska): Metal accumulation and antioxidant enzyme activity. - Int. J. Mol. Sci. 20: 4355, 2019.

Mataa M., Tominaga S.: Effects of shading stage and level on fruit set and development, leaf carbohydrates and photosynthesis in ponkan (Citrus reticulata Blanco). - Jap. J. Trop. Agric. 42: 103-110, 1998.

Matsuda R., Suzuki K., Nakano A. et al.: Responses of leaf photosynthesis and plant growth to altered source-sink balance in a Japanese and a Dutch tomato cultivar. - Sci. Hortic.-Amsterdam 127: 520-527, 2011.

McClure K.A., Cline J.A.: Mechanical blossom thinning of apples and influence on yield, fruit quality and spur leaf area. - Can. J. Plant Sci. 95: 887-896, 2015.

Morais P.L.D., Filgueiras H.A.C., Pinho J.L.N., Alves R.E.: Relationship of fruit growth variables of 'Tommy Atkins' mango. - Cienc. Agrotec. 28: 743-747, 2004.

Parvizi H., Sepaskhah A.R.: Effect of drip irrigation and fertilizer regimes on fruit quality of a pomegranate (Punica granatum (L.) cv. Rabab) orchard. - Agr. Water Manage. 156: 70-78, 2015.

Pinkard E.A., Beadle C.L.: Aboveground biomass partitioning and crown architecture of Eucalyptus nitens following green pruning. - Can. J. For. Res. 28: 1419-1428, 1998.

Poni S., Gatti M., Palliotti A. et al.: Grapevine quality: A multiple choice issue. - Sci. Hortic.-Amsterdam 234: 445-462, 2018.

Sairam R.K., Deshmukh P.S., Shukla D.S. et al.: Tolerance of drought and temperature stress in relation to increased antioxidant enzyme activity in wheat. - J. Agron. Crop Sci. 178: 171-178, 1997.

Suzuki T., Kohno K.: Effects of pruning on the branching habit of Morus alba L. and the abscission of the apices of the short shoots. - New Phytol. 106: 753-758, 1987. 
von Bennewitz E., Fredes C., Losak T. et al.: Effects on fruit production and quality of different dormant pruning intensities in 'Bing'/'Gisela ${ }^{\circ} 6$ ' sweet cherries (Prunus avium) in Central Chile. - Cienc. Inv. Agr. 38: 339-344, 2011.

Wang L.T., Lv M.J., An J.Y. et al.: Botanical characteristics, phytochemistry and related biological activities of Rosa roxburghii Tratt fruit, and its potential use in functional foods: a review. - Food Funct. 12: 1432-1451, 2021.

Wertin T.M., McGuire M.A., Teskey R.O.: The influence of elevated temperature, elevated atmospheric $\mathrm{CO}_{2}$ concentration and water stress on net photosynthesis of loblolly pine (Pinus taeda L.) at northern, central and southern sites in its native range. - Glob. Change Biol. 16: 2089-2103, 2010.

Wibbe M.L., Blanke M.M.: Effects of defruiting on source-sink relationship, carbon budget, leaf carbohydrate content and water use efficiency of apple trees. - Physiol. Plantarum 94: 529-533, 1995.

Wu B.J., Chow W.S., Liu Y.J. et al:: Effects of stomatal development on stomatal conductance and on stomatal limitation of photosynthesis in Syringa oblata and Euonymus japonicus Thunb. - Plant Sci. 229: 23-31, 2014.

Yang H.Q., Jie Y.L. Zhang L.Z. et al.: [Effects of root pruning and shoot pruning on water use efficiency of apple leaves.] Acta Hortic. Sin. 29: 197-202, 2002. [In Chinese]

Yoshida T., Chen X.M., Hatano T. et al.: Tannins and related polyphenols of rosaceous medicinal plants. IV. Roxbins A and B from Rosa roxburghii fruits. - Chem. Pharm. Bull. 35: 1817-1822, 1987.

Zhang C., Zhang D.W., Deng X.G. et al.: Various adaptations of meadow forage grasses in response to temperature changes on the Qinghai-Tibet Plateau, China. - Plant Growth Regul. 88: 181-193, 2019.

Zhang J., Kirkham M.B.: Drought-stress-induced changes in activities of superoxide dismutase, catalase, and peroxidase in wheat species. - Plant Cell Physiol. 35: 785-791, 1994.

Zhang X., Zhai M., Xu Y., Li Y.: [Effect of different pruning measures on branch growth and carbon-nitrogen metabolite accumulation in branch and leaf of Carya illinoensis.] J. Plant Resour. Environ. 23: 86-93, 2014. [In Chinese]

(C) The authors. This is an open access article distributed under the terms of the Creative Commons BY-NC-ND Licence. 